\title{
Mentalization Based Treatment (MBT): A Possible Theoretical Frame for Music Therapy Practice in Clinical Psychiatry
}

\author{
Niels Hannibal ${ }^{1}$, Melody Schwantes ${ }^{2}$ * \\ 1 Aalborg University, Denmark \\ 2 Appalachian State University, United States \\ *melodyschwantes@gmail.com
}

Received: 21 November 2016 ; Accepted: 20 February 2017 ; Published: 1 July 2017

Editor: Tríona McCaffrey Reviewers: Inge Nygaard Pedersen, Susanne Metzner

\begin{abstract}
The mentalization based treatment (MBT) model may be a valuable theoretical perspective for music therapists to consider using with clients in need of mental health care, particularly those with borderline personality disorder. This article explores some of the basic principles of MBT and its application to music therapy. We have included a case study and reflections for further consideration. It is our hope that music therapists will begin to incorporate this model within their treatment and care of clients with psychiatric disorders.
\end{abstract}

Keywords: mentalization based treatment, borderline personality disorder

\section{Introduction}

A woman was playing an improvisation together with me (NH), her music therapist. It was our first session. She was in her 40s. She was slim, well-dressed with makeup and hair in order, and not very tall. She seemed calm and appeared to be nothing out of the ordinary. In the first session, she quickly told me about a traumatic loss of her fiancé who died in an accident 20 years ago. She presented this loss with no emotion and still gave me the impression that she had not yet processed this traumatic event. After talking some more, we engaged in playing an improvisation together on two separate pianos facing one another. She played one note at a time, simply playing like there was only the next note. I accompanied her note while playing a stable grounding rhythm, a few notes, and sometimes some simple chords. There was little progression in the music. Then, the music began to form, a simple melody coming from her, and a simple harmonic ground coming from the therapist, added to a stable pulse. The music had an emotional quality, quiet, maybe sad, or even peaceful. She stopped and said it was peaceful. She associated being at peace with being dead, and suddenly the process of therapy took a new turn. The intimacy level changed. What were only tones on a piano became a wish to die. The intensity of the emotions in this newly formed relationship with the therapist was almost overwhelming, and for the following weeks and months engaging in music became difficult and threatening for her. What happened? How can we understand this process? 
In this paper, we will present the mentalization based treatment (MBT) model as a theoretical model that can help define the process of music therapy. The model originates from verbal therapy (Fonagy, 1989; Fonagy, Gergely, Jurist, \& Target, 2002; Fonagy \& Luyten, 2009), however it is our belief that it is well-suited to music therapy and actually supports our methods and thinking about music therapy in psychiatry in very effective ways. It also challenges and brings a new perspective to the role of the therapist. This article aims to demonstrate why MBT is a new and suitable theoretical model for music therapy. While theories in music therapy have been established and utilized by clinicians internationally (Bain, Grzanka, \& Crowe, 2016; Chwalek \& McKinney, 2015; Rolvsjord, 2010; Silverman, 2015; Solli, Rolvsjord, Borg, 2013), theory about clinical work is in constant development.

Music therapists often use the theoretical framework related to the treatment context in which they work. Every clinical setting has its preferred focus points and treatment agenda reflected in some sort of theoretical model. When we as music therapists work in such a setting, we have to be able to communicate the process and outcome of therapy with our clients to the interdisciplinary team. We need some kind of mutual theory and understanding as a bridge between music therapy and other forms of treatment. In this article, we present the view that since we cannot be non-theoretical we have to be explicit about the theory we use. It is therefore important to be clear about our theoretical framework when we describe our clinical practice.

In this case report, we want to elaborate on how MBT can be relevant for discussing, understanding, and communicating about music therapy specifically with people with personality disorders. Clients with personality disorders and especially clients with borderline personality disorder (BPD) have unstable relationships, intense and unstable emotional states, and self-destructive behaviour. They experience emptiness or are overwhelmed by emotions that they do not understand (they cannot mentalize), and as a survival strategy they project their feelings, and use splitting and denial to keep their internal balance. They are often in distress, and their state of mind or their emotional state can change in an instant. This is why their relationships are so unstable. For more information see Bateman and Fonagy (2007).

There are two main reasons for choosing MBT with clients with personality disorders. First, MBT is a treatment concept that is used worldwide in the treatment of people with personality disorders, particularly BPD (Bales, van Beek, Smits, Willemsen, Busschbach, Verheul, \& Andrea, 2012, p. 569; Kvarstein, Pedersen, Urnes, Hummelen, Wilberg, \& Karterud, 2015, p. 72). The journal Personality Disorders: Theory, Research, and Treatment even published an entire issue in 2015 on the use of mentalization in the treatment of individuals with BPD. Mentalization utilizes the preferred clinical language that is used in many interdisciplinary teams in psychiatry (Bateman \& Fonagy, 2007; Choi-Kain \& Gunderson, 2008). It is the context language. It is therefore relevant for music therapy as a profession to be able to understand and possibly work within this frame. Second, the MBT community has paid very little attention to music therapy and what it can contribute to the model. We believe that music therapy can contribute something important here. What and how are the questions. In order to add to the MBT model we want to present this case and by doing so describe and unfold how we can understand what happens in music therapy from an MBT perspective. The paper will begin with a brief summary and background of MBT, followed by a case example on how the client's attachment systems were activated and changed during the treatment, and how both active and receptive music therapy methods were utilized.

\section{What Is Mentalizing And What Is MBT?}

The term mentalization was first mentioned by researchers from the Ecole Psychosomatique de Paris who also worked with theory of mind (Bateman \& Fonagy, 2010, p. 11). Bateman and Fonagy (2006) took their work and developed the concept in the field of mental disorders. To mentalize is the ability to think, feel, and observe mental processes in others and in ourselves. Bateman and Fonagy (2010) explained it this 
way: "Mentalization, or better mentalizing, is the process by which we make sense of each other and ourselves, implicitly and explicitly, in terms of subjective states and mental processes" (p. 11). MBT is a treatment model that was developed by Fonagy and Bateman and others more than 20-years ago (Fonagy, 1989).

Mentalizing is defined as a form of "imaginative mental activity about others or oneself, namely, perceiving and interpreting human behaviour in terms of intentional mental states (e.g. needs, desires, feelings, beliefs, goals, purposes, and reasons)" (Fonagy, Bateman, \& Luyten, 2012, p. 3). Mentalization is rooted in the psychoanalytic approach, specifically attachment theory. MBT is also influenced by neuropsychology, cognitive therapy, and systemic theory. It is a hybrid theory and in that respect, is not new. However, it is the combination of these different theories and how they are used in the context of psychotherapy with a client with personality disorder that is the new element. MBT sees the process of therapy in the here and now, as influenced by both the client and the therapist, in a context of relationship where attachment patterns are often ambivalent or disturbed. The developers of the process believe that when the social affiliate system is disrupted in the attachment process, this disruption can cause serious and complex mental health problems.

One central and important element of MBT is the integration of attachment theory (Fonagy, Bateman, \& Luyten, 2012). Attachment theory deals with how children establish the ability to have trusting relationships with significant others. Attachment patterns develop very early and influence our perception of ourselves and others at a very fundamental level. When the attachment system forms, it provides a preverbal, implicit level of schemes of how to be with other people. It is similar to Stern's (1991) concept of RIG's ${ }^{1}$ and "schemas of how to be with another" person (p. 120). People with personality disorders often have insecure attachment systems (Choi-Kain \& Gunderson, 2008, p. 1129) and their attachment patterns are either ambivalent or disorganised. This means that when their attachment system is stimulated in interaction with other people, the person can experience increased arousal, fear/freeze, or flight responses. This response can inhibit the capacity to use the prefrontal cortex. The prefrontal cortex gives a person the ability to reflect and think. It also plays a part in emotional regulation because the prefrontal cortex is active in the mechanism used to inhibit our emotional responses. We can enforce some level of voluntary control over our emotional responses. However, because of the way the brain works, this part of the brain can also be inhibited by the limbic system and the amygdala, which are in control of the most basic instinctual responses to any stimuli. When arousal gets too high, the ability to mentalize is lost. We cannot think and we cannot regulate our emotions. We are caught up in the arousal and this compromises our ability to reflect and act. The capacity to mentalize is as easily lost in a therapeutic setting as in any other context. Phenomena like transference reactions and psychic defense mechanisms are signs that the psyche is under pressure. Something in the context of the therapy has triggered this response. It can be anything: words spoken, a glance at the clock, a sigh. It can be any expression or communication from the therapist that is interpreted by the client as dangerous, for example, the therapist may be initiating a more personal therapeutic relationship. The client knows that getting close to someone is synonymous with high risk of being abandoned, or the client cannot tell if the friendly face is actually friendly or not. These are ways in which the attachment system is activated, and if the attachment system is over stimulated it can trigger a mentalization breakdown. This can happen in a millisecond.

The MBT model was designed as an intervention model to treat clients who have problems with interpersonal relationships and their sense of self, because their ability to mentalize broke down easily. This meant that these individuals were especially vulnerable in interpersonal relationships. They could be caught up in perceptions of themselves and others that were based more on a misinterpretation of the actual context and events than on what was "actually" going on. They would lose the ability to look at events from a broad perspective. They would lose the ability to mentalize. This is thought to be an essential trait in people with personality disorders. 
The loss of the mentalizing capacity can happen for the therapist as well. The concept of countertransference can include this phenomenon. When the therapist loses the ability to mentalize, he or she has to restore this capacity before they can continue mentalizing the client. This is important because a client develops and learns to mentalize by being mentalized. So what does this imply? It implies that in order to help a person restore the mentalizing capacity we have to do two basic things: we have to help regulate the arousal level to the optimal level (not too much and not too little) and we have to help the person to start thinking about their own mental states (thoughts, feelings, actions, etc.). Emotions can be regulated in many ways, but the basic principal is to validate the client's reality and to contain whatever emotions they experience and express.

Attunement and non-verbal communication are important here because the therapist not only has to say that he or she accepts what the client experiences, but also has to show that he or she accepts it through posture, tone of voice, and eye contact for example. This process and these factors feature in the Boston Change Process Study Group's writings (BPCSG, 2010, p. 15) about the implicit negotiation of the therapeutic relationship. By engaging in this way, the therapist shows that they are no threat to the client and their experience. This also has the consequence that the clinical focus of MBT is on the immediate context of the here and now. Something happened right here and right now, and we want to know what it was.

To work in the on-going here and now context is an essential part of gestalt therapy and other existential therapeutic orientations. However, to choose this focus and to combine it with a dynamic theoretical understanding of the treatment process and the meta-psychological understanding of the client's internal dynamic is new. When arousal is optimal, the therapist has to introduce the next element in this phase of the process. The therapist has to help the client to start reflecting. This is done by asking, "what do you think?" or "I am wondering..." instead of telling them what you think or interpreting what happened. In MBT this is known as the not knowing stance. We want the client to start to reflect. This means that the goal of the treatment is not for the client to achieve some kind of insight into a specific traumatic event, but to internalise and reconstruct the ability to think and respond in a mentalizing way. The MBT model has certain implications for the therapist's way of being present in the relationship with the client. The therapist has to help to regulate the client's arousal level. The therapist has to perform a not knowing stance. The therapist has to investigate the client's thinking when it shows signs of loss in the mentalizing capacity and only reflect and mirror emotions that are clearly marked. The MBT model can be described by these basic principles ${ }^{2}$ :

- Focus on the here and now;

- Focus on both implicit and explicit levels of communication;

- Cultivate a not knowing stance in the sense that no intervention or method is used if it means diminishing the ability to mentalize;

- Strive to maintain a mentalization-enhancing attitude towards the client in the conversation and in the non-verbal communication;

- Identify dynamic patterns such as defense, transference, and counter-transference; but only use them to enhance understanding of the ongoing unfolding interaction;

- Do not encourage fantasies and free associations about the therapist;

- Do not use confrontation and frustration-inducing interventions such as long periods of silences;

- Do not mirror unmarked emotions.

\section{MBT in Music Therapy}

These guidelines have some implications for the music therapist and raise some questions. First of all we have to find out how a person can mentalize through music. In active music therapy we often use improvisation as a way to help the client to engage and express themselves with less focus on words and more focus on emotion and 
the body. Improvisation enhances the implicit level of communication and interaction (Hannibal, 2000, p. 309). This can be helpful for a client who gets stuck using words or gets stuck in the process in other ways, because music offers a medium that directly reveals us. If a client tries to express anger, but plays very softly or quietly, this shows us something about the client's ability be angry. It is difficult for the client, and it potentially creates a high level of arousal. If the relationship between the client and the therapist is strong enough, and the therapist's musical response is adequate, the client might experience relief. This relief could increase the ability to regulate and contain the emotion. On the other hand, it might also create a mentalizing breakdown, and decrease the client's mentalizing capacity. Sometimes music makes the implicit explicit.

For example, a woman was playing with a male therapist. He felt the music was flowing and began to be more initiating and active. After the music, the woman turned to the therapist and shouted "is it you or me who is in therapy?" They listened to a recording of the music, and the client was surprised when she heard what happened in the music. She was surprised that she had experienced the episode so intensely. In reality, the therapist had left his mirroring and attuning position for about 15-seconds, but it was long enough for the client to have a strong experience of loss of attention and support. So, active music therapy and improvisation may create an environment that enhances the implicit level of interaction, which might be a more direct or a more subtle way of engagement, where the attachment system and the relationship is primarily negotiated through the attachment system and implicit relational patterns. This is another way of saying that improvisation also holds the potential to trigger fear, flight, or freeze mechanisms as well as an attuned, regulated optimal response. Or as Strehlow and Lindner (2016) describe: musical activities can be viewed as supportive or threatening by the client, and the therapist can be someone the client dares to be close to or someone the client turns away from. This can change very quickly.

MBT is understood as mental activity on both the implicit and explicit level, an important point to consider in music therapy. This means that the treatment model incorporates explicit thinking such as words, symbols, narratives, or the what level. Implicit procedural activity such as body language and unconscious phenomena are the how level. Music accesses both levels simultaneously, so music therapy may have the capability of enhancing mentalization.

Active music therapy may consist of songwriting where a personal statement or a narrative can be expressed. Songwriting can help formulate and integrate the implicit and explicit qualities of music as songwriting combines the implicit and dynamic elements of active music therapy with explicit symbolic, verbal, and narrative elements. It enhances the aesthetic element of music therapy and also includes a gestalt or a final product. Songwriting may have two or more dimensions. It is created in a therapeutic process, it is something final that can be sung, recorded and listened to, and it can be shared if this does not violate the therapeutic frame (Baker, 2015). All of these parts of therapeutic songwriting hold potential for the mentalizing process.

Active music therapy can also consist of playing pre-composed songs. Songs can function as a safe haven and/or as a personal statement. Singing a pre-composed song can function as a personal statement and also as a transitional object that provides safety. The singing in itself has a therapeutic component since it activates breathing, vocalisation, and emotional expression. These are often compromised for people who enter psychiatric treatment (Wich, 2013). Music therapy may also incorporate receptive methods such as listening to music. For example, a client with very severe depression chose a German song by Rammstein called "Spring" (in English "Jump"), when he was too exhausted to talk about being depressed, using the tune to communicate how he felt. This heavy metal song is about a man who stands on a bridge about to commit suicide by jumping. The crowd is watching below and they cry: Jump!

Thus, the MBT model has many implications for music therapists, since musical activities engage the therapeutic relationship on the implicit level. Working in the here and now is an essential part of music therapy and the therapeutic process has a natural focus on both implicit and explicit levels of communication. The not knowing stance is 
a bit more problematic to translate directly into a musical context. It requires that the therapist recognize when he or she is driven by internal ideas and thoughts and not focused on making the other person work. Working with not knowing is also different in music. On one hand, the music therapist is used to engaging with the client without knowing the explicit meaning of the music and that is an advantage; on the other hand, the music therapist uses countertransference and other internal perceptions together with the client's musical communication as a guide. Instead of making "sense" of the music understood as meaningful, we have to make sense of the music from a relational perspective. The client is doing something and we are responding to what they do, and not what is meant. Here music therapists have different options. We might offer a stable rhythm for them to lean on, even though they implicitly expect the significant other to be unpredictable and elusive (transference). They might reject it and change their style of playing and we aim to validate their implicit "choice" not to receive our offer to support. And yet we might again provide stable musical frame that is attuned to their musical style of playing. In that sense we can validate what they are doing and at the same time communicate stability: "You want to do something else, and that is okay". The point is that we want to acknowledge their state of mind and at the same time show and offer our presence, attention, and empathy. We regulate ourselves so that we do not try to manipulate the client. We try to show acceptance and recognize their state of mind by mirroring and matching their playing, and at the same time we show our presence and intention in the relationship. So playing together without knowing is what we are trained to do. So it is certainly possible to meet the client with a not knowing attitude.

Working in the relationship and in the music with a dynamic perspective on the process is mandatory in analytical music therapy, and it requires advanced training. The element of free association about the therapist is difficult to control and regulate when the interaction is based on music and not words. This is why clients sometimes have strong negative reactions to free improvisation. It activates transference patterns. Even if the therapist reassures the client about being non-judgmental and everything in the music being allowed, this is sometimes not enough. The client has to experience this; building trust in the music takes time.

Finally, there is the element of marking emotions. Dynamics are different in a musical context. On one hand, there is no marking of anything by anyone, because improvised music is non-discursive and holds no exact meaning. We cannot take a musical statement and understand it in the same way as a verbal statement. So we can play anything and never know what it means. This can be an advantage, because it allows clients to express themselves without having to account for what it means. They can experience the power of expression and communication. But there is also the risk of both hiding in the music and lack of regulation and attunement. On the other hand, it is clear who played the loud angry note; who hit the drum, who played the sad melody, or who played the sad piano, particularly if the improvisation was recorded. Action and expression clearly mark the origin of an emotional expression, and therefore music expression also can be experienced as vulnerable communication.

Returning to the initial statement that we, as music therapists, should work from some type of model when we do treatment, how can MBT influence our thinking? First of all, we are aware of keeping our focus on what goes on in the here and now, and also having a focus on the implicit and explicit level of interaction and mental activity. At the same time, we must be very much aware about what happens to us while engaging in the relationship in terms of emotions, thoughts, images, associations, bodily sensations, impulses, and sudden ideas that emerge out of nowhere. We need to monitor our own capacity to mentalize and to keep the focus on not knowing and tryng to see the client from the inside. Likewise we should try to analyse and observe the client's behaviour and communication to assess the level of mentalization. 


\section{Pre-mentalizing}

We need to pay attention to the client's cognitive style to see if there are signs of prementalizing states called: pretend mode, teleological stance, or psychic equivalence. These different cognitive styles are often indicative of a low level or lack of mentalization (Choi-Kain \& Gunderson, 2008). Pretend mode is when a person appears to mentalize, but their mental activity is based on no connection between inner and outer reality. For example, this might be when a client is describing something traumatic, but there is no emotional connection. This can also happen in the music when a person aims to express an emotion, but the music is empty. Teleological stance is when the only way a person understands mental activity is by their physical appearance. It's what a person does that matters. Internal states of mind have no importance. Examples might include a glance at the clock, a sigh, or a cancellation of a session. These actions are the basis of which the client understands "the other". In music therapy, this type of pre-mentalization often happens when the use of music to communicate and relate is unfamiliar and therefore can be threatening. For example, a client has an outburst of anger, accusing the therapist of filling the whole "space" in the music after an improvisation. In this moment of space, the therapist, for a short period, felt there was room and a sense of being partners in the music. Listening to the improvisation afterwards helped the client to acknowledge her sensitivity to other people in a situation where she thought she was the focus of attention. Psychic equivalence is when the inner world of the client and the outer world fuse together. One example might be when a client is playing an instrument that makes them anxious and, therefore, playing is experienced as dangerous. Finally, we should register the level of emotional arousal. Keeping the arousal level optimal is essential.

\section{Case Example}

Laila was a woman in her early 40s. She was married and had two teenage daughters. She experienced a stress disorder, was sent on sick leave, and then was dismissed from her job. In her paperwork, she was described as being sad, having low self-esteem, and feeling unmanageable. She cried easily. She was diagnosed with paranoid personality disorder; compulsive personality disorder, and disturbed personality mixed type. Music therapy began a year after she experienced her stress disorder.

In the first session, as described initially, I (NH) met a woman who was not very tall, well-dressed, and with make-up in place. I experienced her as both inconspicuous and pretty at the same time. She began the session by telling me that she has been depressed for a long time, since losing her first big love who died in an accident some 20 -years ago. She had only cried once. This traumatic event had never been processed, because her mother was always crying and did not pay attention to Laila's sadness. There was no room for her grief. She quickly found another boyfriend and they married. She described her husband as a person she married for safety more than for love. She told her story with a neutral tone of voice and no emotions were shown. When asked why she stayed in her marriage, she said that she had no wish for a divorce, since the feeling of security was essential to her. She was a security addict.

She described her childhood as normal. Her parents spent a lot of time in the garden. She spent a lot of time on her own with her brother and she felt attached to her father. At the same time, she described her father by describing how he sometimes bragged about his pretty daughter in front of friends, and then asked her to leave so he could be with his friends without her. He sometimes made fun of her and humiliated her when she was standing in front of a mirror at home to make herself look pretty. She also talked about how she wanted her father to put her to bed, but that he refused because he was afraid it could be seen as incestuous. Her father had an alcohol problem for many years, but he did not drink anymore. Her parents were divorced. When describing her mother, she talked about the feeling of wanting to sit on her mother's lap, and that she would do this a lot during childhood. She was anxious and needed her mother to calm her down. She described her mother as dominating. When they 
were together, her mother insisted that her opinion was the only valid one. If they ever disagreed about something, her mother would threaten to leave if her opinion was not respected. Laila had been dependent on her mother in her daily life because her husband was a sailor in the merchant fleet. Her relationship with her mother made her feel powerless and frustrated. Laila's husband was a calm man and at the beginning of therapy she described him as someone who did not pay enough attention to her or notice her in the way she needed. Intimacy was difficult, and her sexual life was not satisfying. At the same time, her husband was also described as someone who listened to her and supported her. She gave me the impression of being bored with her marriage.

When Laila described her children, she said that she found it difficult to engage with them and to relax at the same time. She felt as if she was highly demanding of herself. She did not let anyone help when she cooked or worked because she did not want other people to take credit for her achievements. However, she felt that she was not valued and that her effort was not recognised or validated. She never seemed to have a sense of achievement and mastery. She was preoccupied with what other people thought about her or was over-involved with others.

Looking at her relational story from a transference perspective gave me the impression that there were many echoes of problems in the attachment relationship that could potentially trigger arousal. The general impression was that Laila could not mentalize when it came to her relationship with these primary people. Her attachment style was ambivalent or over-involved. She had some mistrust of other people that triggered paranoid thoughts about "the other". She also had some unresolved grief from the traumatic loss that she had never processed. In combination, this pointed to potential problematic relational issues and patterns that might emerge in the therapeutic relationship. If Laila wanted admiration from men, there could be a fear of humiliation and exposure, or neglect and a lack of interest. If she needed support and help from women, there could be a risk of being dominated and also a threat of abandonment. There was no room for her point of view. If she needed to process loss and grief, she was afraid of being denied comfort and emotional support.

Laila attended 36 of 40 available sessions. Reflecting on these sessions, the therapy was divided into three phases from an intervention perspective. Three types of interventions were used. Active music therapy was used in the beginning and end of treatment to work with interpersonal issues. Receptive music therapy was used in the middle to access the traumatic events in her life, and verbal therapy was used throughout therapy.

Phase one Phase one lasted from session 1 to 14. During this phase, Laila was introduced to active music therapy in the form of improvisation and she also brought her own music to the therapy, which we listened to together. As can be seen in the more detailed description given below, active music therapy was first something that opened her up and produced an emotional connection, but it was overwhelming to experience and share these emotions. She was then encouraged to bring music that was meaningful and important to her, and she did. Then we played/improvised some more, without the same emotional intensity, and she disengaged from the music and was bored. I was unsure whether she would drop out or not.

Phase two In phase two we introduced receptive music therapy, where the client lay down on a mat, with eyes closed, and listened to selected pieces of classical music. While listening to the music, Laila described her mental activity. This worked very well for her and her internal images were focused on her primary relationships, her loss, and her situation in the here and now. She encountered her history and began to process her idealised picture of the lost relationship. This phase lasted until session 25.

Phase three Phase three began in session 26 when she suddenly said: I want to address "my personality disorder issue." Immediately, her therapeutic focus was on relationships and the here and now, the daily issues related to people in her life, being required to start work again, her children, her mother, and her life. The main focus was her wish to be less concerned with other people's thoughts. We worked with this 
in the music and in a verbal context. In the final session, we improvised again, and her experience was very different from the first session. Comparing the first and last piece of musical interaction and expression illustrates the development of new attachment patterns and new ways of viewing and regulating her internal emotional world.

\section{Examples of mentalization breakdown and recovery in the music}

In the first session, we played for 5-minutes. Laila was given the simple instruction to play one note at a time whilst I provided a regular pulse with a few notes. Her single tones related to my tones, and even though she did not play a melody that had clear phrases and melodic structure, we shared the volume, the tempo, and the tonality. We shared an experience of musical contact. The music was slow and gentle in quality. Suddenly she was very moved by the music. It made her feel at peace, but a feeling of peace associated with the wish to be dead. The emotions were mixed and confusing, and she seemed surprised by this experience. The event showed that these emotions were near to her psychological surface and that sharing them was unfamiliar. She also thought about her lost love.

In the context of attachment and mentalization the music seemed to promote both positive and negative feelings, and this dynamic created a breakdown in her capacity to mentalize as it brought her in contact with suppressed emotions. She was overly concerned with exposing herself, and sharing emotional content made her feel unsafe. The music had suddenly made her appear to say, "I want peace; I want to die." The musical experience and her inner response were linked. This is called the psychic equivalence mode (Bateman et al., 2007); inner reality becomes reality. Even I was surprised by the impact of this experience. Being the first session, I needed to focus both on containing and clarifying these emotions and her thoughts about them. Even though we played again in the next sessions she did not get involved in the same way. The intimacy and the exposure had been an intense experience. As a means to empower her, I suggested that she bring her own music. She brought a tune that she related to her traumatic lost relationship, and she processed some of these emotions. But playing seemed to suddenly have lost its attraction. My countertransference feelings included doubt about the alliance and thoughts about her potential dropout from treatment.

In the second phase, the listening experiences moved her back on the therapeutic track. When lying down and listening to music, she could receive the music in a passive position and be in control. At the same time, she could surrender to the music and my voice. She worked hard. Her images revealed how her lost love constantly appeared in her thoughts, and how attractive and colourful he seemed in contrast to her grey and detached daily life. The images often included the element of jumping off something like cliffs or bridges. She was in touch with her grief and her desire to end her life. A more diverse picture of the relationship also began to emerge. In the verbal dialogue she included a more complex and less idealised picture of him and their relationship. She finally seemed ready to leave it behind - for now. Other issues emerged such as the disconnectedness that she experienced with her daily life. It appeared that she also experienced postpartum depression, a passive eating disorder, and bullying in the workplace.

From a mentalizing perspective, this receptive music therapy process seemed to enhance her ability to mentalize herself. I could validate and support her internal state and she could experience me in relation to herself unfolding. Her rigid representations of her loss and life began to crumble, and a more flexible and negotiable picture began to emerge.

Phase three was much more focused on relationships. There were issues such as conflicts with a neighbour, how to deal with the cooking on Christmas Eve, anxiety about her work situation, her fear of making mistakes because it is so difficult for her to remember things, and her need for admiration and confirmation, to mention only a few points. There was a special focus on her wish to be less concerned with what other people think about her. She used the music to explore emotions such as confusion and 
anger related to situations in her daily life. In the last session, she engaged in a musical improvisation about termination of therapy. The music was more fluid in style and dynamics. The roles in the music between Laila and me were the same as in the first example, but her ability to engage and cope with sudden changes was clear. She was not overwhelmed by emotions and her attachment system was not over-stimulated. We even played another improvisation about the future.

She reported afterward, when terminating therapy, that she experienced herself as more safe in relation to me and how annoying it was to have to start all over again in another setting. She felt more open and honest towards me. She was more aware of how she perceived others and wished she were less suspicious. Laila was still concerned about what other people said about her. She felt better, but still sad deep down. She had begun working a few hours a week and was managing the stress that being in a working environment sometimes creates. She began to enjoy things and not only to focus on whether everything was perfect.

\section{Discussion}

In reflection, we would like to discuss how aspects of MBT and music therapy could contribute to one another and also reflect on ways in which MBT could impact our work as music therapists. The question still remains: can music therapy practice be altered by MBT or is MBT even directly transferable to music therapy?

To have the client's mentalization as the focus of the treatment process can improve our verbal therapy skills as music therapists. The guidelines described earlier provide clear directions as to how the therapist can try to enhance the client's mentalizing capacity. In reality, some of the recommendations, such as the focus on the here and now, the not knowing stance, and the inclusion of the therapist's actions are amenable to combining this treatment and music therapy. The role of the music therapist traditionally has been in conflict with conventional psychoanalytic recommendations about having a more passive and observing position. In active music therapy, the therapist has to be engaged and what unfolds in the relationship is very much influenced and guided by the actions in the music of both the therapist and the client. So MBT and music therapy share the same view of the role of the therapist. Here, the therapist has an active part in the ongoing relationship. However, since the focus of the treatment is on the client's mentalizing capacity, and since we are really only beginning to understand musical interaction from this perspective, the knowledge we have is currently more hypothetical.

In active music therapy, musical interaction can be viewed as preverbal interaction (Hannibal, 2000; 2014). The music enhances the implicit level of the client's and the therapist's relational patterns. This means that clients have an opportunity to experience how they interact with other people, but in a nonverbal medium. The client senses at a tacit level how the therapist engages relationally at the micro level. In the example from the first session, Laila initially viewed the task as a simple task of producing some tones on a keyboard. The tones were met, regulated, contained, and mirrored back to her. She may not have been aware of this process, but she responded to the invitation by the therapist. This produced both a positive feeling of peace and also associations about how to experience peace. Here the teleological mindset created an unimaginable scenario of taking her life as the only way to achieve peace. The example illustrated that sometimes the musical activity can make the client vulnerable and that the capacity to process this vulnerability might not be there in the moment. It also illustrated the relational power of a musical interaction. The music created a relational matrix where the client experienced his or her relational patterns.

In MBT it is recommended that the therapist stop and spool back to where the mentalization capacity was influenced by the process. This movement is easily done in a verbal context, but what does it imply in a music therapy context? Can we stop and spool back? This is often not possible in the here and now of the process. It is simply too difficult to identify when it happens. However, what does often happen when a 
client loses the ability to mentalize is that they stop playing. They try to regulate the emotional level of the situation by terminating the music and this is good. If the music has been recorded, then the therapist and the client can listen back to the music together and explore what happened as described above. Even without a recording it is possible to investigate the incident retrospectively. So stopping and spooling back is also possible in music therapy. The musical process can of course be investigated in the verbal context as it was in the example above. This way of working has a long history in music therapy (Hannibal, 2013, 2014, 2016) and it could be argued that music therapy has in this sense preceded MBT.

Another issue relevant to music therapy is the element of pseudo-mentalization where the client functions in pretend mode (Bateman \& Fonagy, 2007). When a client is in pretend mode, their reflections about mental conditions have no connection to the actual reality (p. 116). No inner or outer connection. Pseudo-mentalization in a music therapeutic context is similar to this phenomenon, and is viewed when a client plays without engagement in the music. The music becomes a hideout and the client feels safe and in control. When a therapist encounters such a person, he or she has three options: (a) to recognize the client's relational pattern as a way of mastering the relationship, (b) to allow the client to stay in control, or (c) to reflect back to the client that the music is experienced by the therapist as something that is difficult to sense and understand. Allowing the client to stay in control in the music can help the client build up trust and validate the client's relational performance in the hope of gradually encouraging more genuine interaction. The therapist can also try to alter the relationship or to work with the structure in the relationship by implementing different interventions. Depending on the individual client, the therapist may give smaller or more profound musical suggestions, stop mirroring the client's playing, or become more active and challenging in his or her music. All of these musical actions should be seen as changes in the way we are together implicitly. For example, a client can engage in improvisation when the therapist takes the role of a stable person attuning to the client's way of playing. The client gradually acquires more independence in her musical expression and the therapist begins to play in a less supportive and less mirroring way. If the client is ready, meaning the attachment system will not collapse, this engagement may lead to improvisations where the role of both people is more free, dialogic, and essentially based on the ongoing here and now interaction, and not viewed through the glasses of past experiences. There is no breakdown in the mentalizing capacity. If the client is ready, the music will reflect the client's ability to be more flexible in the here and now based assessment of the relationship and the musical expression of the therapist. However, it is a balance as with all therapeutic interventions. There is an imperative need for the therapist to try to mentalize the client. This means that our musical interactions must be based on an understanding of the client's internal world. It is this understanding that we as music therapists use to help the client become more capable of mentalizing verbally and most importantly, to be able to act in a mentalizing way. The case of Laila showed that she could handle a more unpredictable musical interaction at the end of the treatment, and that she was able to express this in words. She was also able to express a deeper understanding of her internal dynamics.

MBT in music therapy is in some sense analytical, dynamic, cognitive, and systemically oriented. But is it resource oriented? Essentially there is no specific goal in MBT guided treatment except constantly trying to keep a mentalizing perspective on the client with the intention of providing an environment where the client's ability to mentalize becomes more explicit and flexible. When we as therapists keep this focus, we intend to empower the client and support their ability to "figure it out." We think of this as a resource. But if the focus in therapy is only on "resources" it is not synonymous with MBT, because this implies, that the therapist focus on the process of therapy from a predefined perspective, and does not initiate the process of therapy from the mental state of the client. And that is what MBT is all about.

To conclude, MBT provides a very valid theoretical frame for music therapy with clients with personality disorders. We see MBT as a theoretical frame that fits well with 
what music therapists have been already doing for many years and believe that MBT challenges classical thinking about therapy and the role of the therapist. Keeping the focus on a person's mentalization level and patterns is not easy without proper training, and that goes for both verbal and music therapy.

\section{Notes}

1. RIG: Representation of Interaction that has been Generalised

2. There are other recommendations such as the therapist's ability to be warm and empathic. These are non-specific factors and therefore are not included here.

\section{References}

Bain, C. L., Grzanka, P. R., \& Crowe, B. J. (2016). Towards a queer music therapy: The implications of queer theory for radically inclusive music therapy. Arts in Psychotherapy, 50, 22-33, http://dx.doi.org/10.1016/j.aip.2016.03.004.

Baker, F. (2015). Therapeutic songwriting: Developments in theory, methods, and practice. New York: Palgrave MacMillan. https://doi.org/10.1057/9781137499233.

Bales, D., van Beek, N., Smits, M., Willemsen, S., Busschbach, J. V., Verheul, R., \& Andrea, H. (2012). Treatment outcome of 18-month, day hospital mentalization-based treatment (MBT) in patients with severe borderline personality disorder in the Netherlands. Journal of Personality Disorders, 26, 568-582, https://doi.org/10.1521/pedi.2012.26.4.568.

Bateman, A., \& Fonagy, P. (2007). Mentaliseringsbaseret behandling af borderline personlighedsforstyrrelse: En praktisk Guide [Mentalization-based treatment for borderline personality disorder: A practical guide]. Copenhagen, Denmark: Akademisk forlag.

Bateman, A., \& Fonagy, P. (2006). Mentalization-based treatment for borderline personality disorder: A practical guide. Oxford, UK: Oxford University Press. https://doi.org/10.1093/ med/9780198570905.001.0001.

Bateman, A., \& Fonagy, P. (2010). Mentalization based treatment for borderline personality disorder. World Psychiatry, 9(1), 11-15, https://doi.org/10.1002/ j.2051-5545.2010.tb00255.x.

Bateman, A.W. (2014) Mentalizing an update. Keynote slids, 2nd Nordic MBT Conference

Boston Change Process Study Group. (2010). Change in psychotherapy: A unifying paradigm. WW Norton \& Company.

Choi-Kain, L., \& Gunderson, J. (2008). Mentalization: Ontogeny, assessment, and application in the treatment of borderline personality disorder. American Journal of Psychiatry, 165(9), 1127-1135, http://dx.doi.org/10.1176/appi.ajp.2008.07081360.

Chwalek, C. C., \& McKinney, C. H. (2015). The use of dialectical behavior therapy (DBT) in music therapy: A sequential explanatory study . Journal of Music Therapy, 52, 282-318, http://dx.doi.org/10.1093/jmt/thv002.

Fonagy, P. (1989). On tolerating mental states: Theory of mind in borderline personality. Bulletin of the Anna Freud Centre, 12, 91-115.

Fonagy, P., Batema, A. W., \& Luyten, P. (2012). Introduction and overview. In A. W. Batemen \& P. Fonagy (Eds.), Handbook of mentalizing in mental health practice (pp. 3-42). Washington, DC: American Psychiatric Publishing.

Fonagy, P., Gergely, G., Jurist, E. L., \& Target, M. (2002). Affect regulation, mentalization, and the development of self. New York, NY: Other Press.

Fonagy, P., \& Luyten, P. (2009). A developmental, mentalization-based approach to the understanding and treatment of borderline personality disorder. Development and Psychopathology, 21, 1355-1381, http://dx .doi.org/10.1017/S0954579409990198.

Hannibal, N. (2000). Praverbal overføring i musikterapi: Kvalitativ undersøgelse af overføringsprocesser $i$ den musikalske interaktion. [Preverbal transfer in music therapy: qualitative study of transfer processes in the musical interaction]. (Published doctoral dissertation). Aalborg University, Aalborg, Denmark 
Hannibal, N. (2013). Mentaliseringsbaseret behandling og musikterapi. [Mentalization and music therapy]. Musikterapi i Psykiatrien Online, 8(1).

Hannibal, N. (2014). Implicit and explicit mentalization in music therapy in psychiatric treatment of people with borderline personality disorder. In J. De Backer \& J. Sutton (Eds.), The music in music therapy. European psychodynamic music therapy: Clinical, theoretical and research approaches (pp. 211-224). London: Jessica Kingsley Publishers.

Hannibal, N. (2016). The future of music therapy for persons with personality disorders. In C. Dileo (Ed.), Envisioning the future of music therapy (pp. 45-52). Philadelphia, PA: Temple University's Arts and Quality of Life Research Center .

Kvarstein, E. H., Pedersen, G., Urnes, Ø., Hummelen, B., Wilberg, T., \& Karterud, S. (2015). Changing from a traditional psychodynamic treatment programme to mentalization-based treatment for patients with borderline personality disorder: Does it make a difference? Psychology and Pscyhotherapy: Theory, Research \& Practice, 88, 71-86, http://dx.doi.org/ 10.111/papt.12036.

Rolvsjord, R. (2010). Resource oriented music therapy in mental health care. Gilsum, NH: Barcelona Publishers.

Silverman, M. J. (2015). Music therapy in mental health for illness management and recovery. New York, NY: Oxford University Press. https://doi.org/10.1093/acprof:oso/ 9780198735366.001.0001.

Solli, H. P., Rolvsjord, R., \& Borg, M. (2013). Toward understanding music therapy as a recovery-oriented practice within mental health care: A meta-synthesis of service users' experiences. Journal of Music Therapy, 50, 244-273, http://dx.doi.org/10.1093/jmt/ 50.4.244.

Stern, D. (1991). Barnets interpersonelle univers. København: Hans Reitzels Forlag.

Strehlow, G., \& Lindner, R. (2016). Music therapy interaction patterns in relation to borderline personality disorder (BPD) clients. Nordic Journal of Music Therapy, 25(2), 134-158, http://dx.doi.org/10.1080/08098131.2015.1011207.

Wich, S. S. (2013). Research into the development of voice assessment in music therapy. (Published doctoral dissertation). Aalborg University, Aalborg, Denmark. 